Review Article

www.ijrap.net

\title{
HERBAL APPROACH IN MANAGEMENT OF NEPHROTIC SYNDROME
}

Choudhary Kuldeep*, Dwivedi Avneesh, Sharma Abhisekh

Department of Balroga, Sri Satya Sai Murlidhar Ayurvedic Medical College and Hospital, Moga, Punjab, India

Received on: 04/12/14 Revised on: 06/01/15 Accepted on: 02/02/15

*Corresponding author

Dr Kuldeep Choudhary, Lecturer, Department of Balroga, Sri Satya Sai Murlidhar Ayurvedic Medical College and Hospital, Moga, Punjab, India

E-mail: kuldeepall@yahoo.co.in

DOI: $10.7897 / 2277-4343.06233$

\section{ABSTRACT}

Nephrotic syndrome (NS) is an important chronic renal disease prevalent among pediatric population. Nephrotic syndrome has emerged as immunological disorder. Researches on pathogenesis have shown $\mathrm{T}$ lymphocyte dysregulation and vascular permeability factors that might contribute the alteration in podocyte function and permselectivity resulting in NS. Prognosis of treatment depends upon steroid responsiveness. Most of them are sensitive initially but later on may relapse or become steroid dependent or resistant to it. Drugs like levamisole, cyclophosphamide, cyclosporine, long term alternate day corticosteroids etc. have been used in combination with various protocols to treat steroid dependent or steroid resistant NS with variable results outcome and more side effects. Hence an alternative therapy is needed. Ayurvedic polyherbal formulation with properties of immunomodulator, nephroprotective and antioxidant properties can prove more beneficial in treating steroid dependent or resistant cases of NS, as add on therapy with modern therapeutic drugs for better results.

Keywords: Nephrotic syndrome, Nephroprotectice herbs, Ayurvedic Treatment, Steroid resistant nephrotic syndrome, steroid dependent nephrotic syndrome

\section{INTRODUCTION}

Nephrotic syndrome (NS) is an important chronic renal disorder in pediatric population. The annual incidence of NS range from 2-7 per 100,000 children and prevalence from $12-16$ per $100,000 .^{1}$ It results due to alterations of perm selectivity at the glomerular capillary wall, resulting in its inability to restrict the urinary loss of protein. ${ }^{2} \mathrm{NS}$ is characterized by heavy proteinuria $(>3.5 \mathrm{~g} / \mathrm{d})$, hypoalbuminaemia (serum albumin $<2.5 \mathrm{~g} / \mathrm{dL}$ ), oedema and hypercholesterolaemia (serum cholesterol $>200$ $\mathrm{mg} / \mathrm{dl}){ }^{3}$ Nephrotic range proteinuria is defined as proteinuria exceeding $1000 \mathrm{mg} / \mathrm{m}^{2}$ per day or spot (random) urinary protein-to creatinine ratio exceeding 2 $\mathrm{mg} / \mathrm{mg}^{3}$ The proteinuria in childhood nephrotic syndrome is relatively selective, constituted primarily by albumin. Nephrotic syndrome can be divided into two types; primary and secondary NS. The NS is usually Primary (Idiopathic) in $95 \%$ cases. An underling etiology might be identified in rest $5 \%$ cases, includes systemic lupus erythematosus, Henoch Schonlein purpura, amyloidosis and infection with HIV, parvovirus B19 and hepatitis B and $\mathrm{C}$ viruses etc. which constitutes secondary NS. More than $80 \%$ patients with NS on renal histopathology shows minimal change disease (MCD) while the remaining show focal segmental glomerulosclerosis (FSGS) and mesangio proliferative glomerulonephritis (MPGN). Membrano proliferative glomerulonephritis and membranous nephropathy are uncommon conditions in childhood $^{4,5}$. Patients with primary NS mostly need immunosuppression (Corticosteroids) to achieve remission, but many of them either relapse after immunosuppression therapy or resistant to it. On the other hand, immunosuppressive therapy is associated with adverse effect. The most important factor that determines prognosis in children with NS is steroid responsiveness. More than $70 \%$ of children with steroid-sensitive NS relapse and almost $50 \%$ have frequent relapses or steroid dependence. ${ }^{2}$ Long term alternate day corticosteroids, alkylating agents (cyclophosphamide), calceneurin inhibitors (cyclosporine, Tacrolimus) immunomodulator drugs (Levamisole) are primary medications used to treat Frequent relapses, Steroid dependence (SD) or Steroid resistant (SR) NS. While many of these are effective regimens in treating $\mathrm{SR} / \mathrm{SD} \mathrm{NS}$ but most of them are associated with side effects like infection, osteoporosis, suppression of bone marrow, corticosteroid toxicity and Hepato - renal toxicity etc. Significant proportions of patients are at risk for complications, progressive kidney disease and end stage renal disease; the lack of efficacy and safety of existing treatment protocols make the treatment of NS a difficult challenge; clearly warranting the need of an alternative treatment. NS has emerged as immunological disorder. Studies have shown that during a relapse the $\mathrm{T}$ suppressor lymphocyte cell activity increases and Interleukin - 2 levels as well as those of tumor necrosis factor-alpha and other permeability factors levels are high. Decreased antioxidant defense and an increase in apoptosis rate contribute to the functional abnormalities of T cell in NS. ${ }^{2}$ Investigation on herbs are revealing the therapeutic benefits of medicinal herbs in treating immunological disorders. Keeping in view of above aforementioned immunological theory in pathogenesis of NS, the herbal drugs possessing immunomodulator, nephroprotective and anti oxidant properties can be used to preserve renal function; in conjunction with modern therapeutic drugs for synergistic effect, lowering potential side effects and to achieve maximum efficacy and safety profile in treating $\mathrm{SD} / \mathrm{SR}$ NS. 
Immunomodulator and Nephroprotective Drugs

\section{Guduchi (Tinospora cordifolia)}

The effect of Tinospora cordifolia was studied on urotoxicity induced by acute dose of cyclophosphamide (CP) using Swiss albino mice model. Administration of an alcoholic extract of the plant $T$. cordifolia $(200 \mathrm{mg} / \mathrm{kg}$ i.p.) for 5 days reduced $\mathrm{CP}(1.5 \mathrm{mmol} / \mathrm{kg}$ body wt. i.p.) induced urotoxicity. It was evident from the morphological analysis of bladder, and also decreased level of urea nitrogen in blood as well as protein in urine. Histopathological analysis of the bladder of $\mathrm{CP}$ alonetreated group showed severe necrotic damage whereas the T. cordifolia treated group showed normal bladder architecture. The lowered levels of cytokines IFN- $\gamma$, IL-2, after CP treatment were found to be increased in treated animals. At the same time the level of pro-inflammatory cytokine TNF- $\alpha$, which was elevated during CP administration, was significantly reduced by extract administration. The study clearly demonstrates uroprotective role of $T$. cordifolia from $\mathrm{CP}$ induced toxicities by modulating GSH and pro-inflammatory cytokine levels. ${ }^{6}$

\section{Ashwagandha (Withania somnifera)}

The root extract of three different doses of $W$. somnifera (viz., 250,500 and $750 \mathrm{mg} / \mathrm{kg}$ ) was administered orally to rats for 14 days before Gentamicin induced nephrotoxicity (GEN) treatment and thereafter concurrently with GEN $(100 \mathrm{mg} / \mathrm{kg})$ for 8 days. Nephrotoxicity was evident in GEN-treated rats by significant increase in kidney weight, urea, creatinine, urinary protein and glucose, and significant reduction in body weights and potassium, which was histopathologically confirmed by tubular necrosis. In contrast $W$. somnifera $(500 \mathrm{mg} / \mathrm{kg})$ significantly reversed these changes as evidenced microscopically when compared to other two doses of $W$. somnifera (250 and $750 \mathrm{mg} / \mathrm{kg}$ ), and there were no significant changes in the levels of sodium in the experimental animals compared to control. Thus, results suggested the nephroprotective effect of Withania somnifera, which could be by enhancing antioxidant activity with natural antioxidants and scavenging the free radicals. ${ }^{7}$ Administration of an extract from the powdered root of the plant Withania somnifera was found to stimulate immunological activity in Balb/c mice. Treatment with five doses of Withania root extract (20 mg/dose/animal; i. p.) was found to enhance the total WBC count $\left(17125\right.$ cells $\left./ \mathrm{mm}^{3}\right)$ on $10^{\text {th }}$ day. Bone marrow cellularity $\left(27 \times 10^{6}\right.$ cells/femur $)$ as well as $\alpha$-esterase positive cell number (1800/4000 cells) also increased significantly $(P<0.001)$ after the administration of Withania extract. Treatment with Withania extract along with the antigen (SRBC) produced an enhancement in the circulating antibody titre and the number of plaque forming cells (PFC) in the spleen. Maximum number of PFC (985 PFC/10 6 spleen cells) was obtained on the fourth day. Withania extract inhibited delayed type hypersentivity reaction in mice (Mantoux test). Administration of Withania extract also showed an enhancement in phagocytic activity of peritoneal macrophages (76.5 pigmented cells/200) when compared to control (31.5/200 cells) in mice. These results confirm the immunomodulatory activity of $W$. somnifera extract. ${ }^{8}$

\section{Haridra (Curcuma longa)}

In an animal model, the nephroprotective and diuretic effects of three medicinal herbs Petroselinum sativum, Eruca sativa and Curcuma longa, alone and in combination were investigated against gentamicin (GM)induced nephrotoxicity in rats. Forty two adult male Sprague Dawley rats were randomly distributed into 6 equal groups, each of 7 animals. The $1^{\text {st }}$ group was injected intra-peritoneally (i. p.) with saline solution $(0.2$ $\mathrm{mL} / \mathrm{rat})$. The $2^{\text {nd }}$ group was i. p., injected with GM (80 $\mathrm{mg} / \mathrm{kg}$ b.wt.) for 8 consecutive days. The other four groups were given orally aqueous infusion of the three herbs, alone and combined, ( $1 \mathrm{~mL} / \mathrm{rat}, 150 \mathrm{mg} / \mathrm{kg} \mathrm{b}$. wt. $)$ along with GM. Twenty four hours after the last administration, blood and urine samples were taken for biochemical analysis. Kidney specimens were taken for estimating oxidant/antioxidant parameters and for histopathology. The results showed that GM induced nephrotoxicity characterized by renal dysfunction as evident by biochemical and histopathological alterations, elevated lipid per-oxidation and reduced activity of antioxidant enzymes in kidney tissues was ameloriated by oral administration of aqueous infusion of Petroselinum sativum, Eruca sativa and Curcuma longa herbs. It caused a nephroprotective effect evident by significant decreases in the elevated serum urea, creatinine and ALP activity and normalized the serum electrolytes level of sodium and potassium. It significantly increased urine output and urinary concentration of $\mathrm{Na}^{+}$and $\mathrm{K}^{+}$; denoting a diuretic activity. It also ameliorated renal tubular necrosis in GMtreated rats. The nephroprotective effect of herbs could be due to the antioxidant effect of these herbs as evident by increasing activity of antioxidant enzymes. Conclusively, the study suggests that mixture of these three herbs may be useful for patients who suffer from renal diseases and those on GM therapy. ${ }^{9}$ In another study the effects of carvedilol, aqueous and methanolic extract of Curcuma longa against cisplatin induced renal damage in Wistar rats was investigated. Wistar rats were randomly divided into 7 groups $(\mathrm{n}=10)$. Rats in group I were normal control received normal saline $(5 \mathrm{ml} / \mathrm{kg}$; i. p.) on day zero, while group VIa and VIb were vehicle control, received carboxymethyl cellulose $(2.5 \mathrm{ml} / \mathrm{kg}$; p.o.) and propylene glycole $(2.5 \mathrm{ml} / \mathrm{kg}$, p.o.) respectively from day 3 to 17 . Renal toxicity was induced in rats of group II, III, IV and $\mathrm{V}$ by a single administration of cisplatin $(7.5 \mathrm{mg} / \mathrm{kg}$; i. p.) on day zero. Rats in group III, IV and V received a daily dose of carvedilol (5 mg/kg; p.o.), aqueous and methanolic extracts of Curcuma longa $(500 \mathrm{mg} / \mathrm{kg}$; p.o.) respectively from day 3 to 17 , while group II served as cisplatin control. Post treated rats with carvedilol and aqueous and methanolic extracts of Curcuma longa for 15 days significantly increased body weight, decreased cisplatin induced abnormalities and mortality and decreased all the kidney marker such as serum urea nitrogen (SUN) serum creatinine ( $\mathrm{SCr}$ ), total proteins 
(TP) and uric acid (UA) increased by cisplatin, however, no appreciable improvement in hematological parameters were observed when compared with cisplatin control. The study concluded the nephroprotective effects of aqueous and methanolic extracts of Curcuma longa. ${ }^{10}$

\section{Varuna (Crataeva nurvala)}

The alcoholic extract of Craaeva nurvala was administered in dose of 250 and $500 \mathrm{mg} / \mathrm{kg}$ for 10 days that showed protective activity against cisplatin $5 \mathrm{mg} / \mathrm{kg}$ induced nephrotoxicicty. The results suggested, that the alcoholic extract has significantly altered the dysfunction of renal proximal tubule cells by decreasing the concentration of blood urea nitrogen, creatinine, lipid peroxidation, glutathione and catalase. ${ }^{11}$

\section{Manjjistha (Rubia cordifolia)}

In a study the hydro-alcoholic extract of Rubia cordifolia was investigated against cisplatin induced nephrotoxicity in Swiss albino mice. Cisplatin at a dose of $12 \mathrm{mg} / \mathrm{kg}$ body wt was administered intra-peritoneally while another set of animals were given hydro-alcoholic extract of Rubia cordifolia at different doses along with cisplatin treatment. The extract significantly decreased the cisplatin induced nephrotoxicity as inferred from the tissue antioxidant status in the drug administered animals. Remarkable change was observed in serum creatinine and urea levels. Lipid per-oxidation in the kidney and liver tissues was also considerably reduced in Rubia cordifolia extract treated animals. The study concluded the nephroprotective role of hydro-alcoholic extracts of Rubia cordifolia. $^{12}$

\section{Badriphal (Hippophae rhamnoides)}

One pilot study showed beneficial effect of the herbal preparation Hippophae rhamnoides as add on treatment in idiopathic nephrotic syndrome. Patients of NS were randomly divided into two groups $\mathrm{A}$ and $\mathrm{B}$, each group comprising of 28 patients. Both groups were treated by standard treatment protocol for specific histological type. In group B standard treatment plus Hippophae rhamnoides $350 \mathrm{mg}$ twice a day was given for 12 weeks as add on treatment. Patients were followed up every two weeks initially and then once in four weeks up to 12 weeks. All patients included in the study were thoroughly evaluated clinically and underwent all baseline investigations as Complete Blood Count (CBC), estimate of Hemoglobin $(\mathrm{Hb} \%)$, Urine analyses $24 \mathrm{~h}$. Urine protein estimation, serum albumin, serum globulin, lipid profile, and specific tests like IL-6, Apolipo protein B and $\mathrm{C}$-reactive protein (CRP). At the end of 3 month patients showed improvement in the symptoms of edema, anorexia, oliguria in the herbal group. The urinary estimation of protein showed significant decrease in Group B with elevation of S. albumin levels. The inflammatory cytokines had showed significant decrease at the end of 3 month. The study concluded the beneficial role of Hippophae rhamnoides as add on therapy in difficult idiopathic nephrotic syndrome patients. ${ }^{13}$

\section{Punarnava (Boerrhavia diffusa)}

The study was designed to investigate the effects of aqueous extract of $B$. diffusa root $(200-400 \mathrm{mg} / \mathrm{kg} / \mathrm{day})$ against acetaminophen induced nephrotoxicity in rats. Animals were randomly divided into the following experimental groups with six animals in each group. Groups I and II served as normal and control, respectively, were orally administered $10 \mathrm{ml} / \mathrm{kg} /$ day of normal saline, while groups III-IV rats were pre-treated with single daily oral doses of $200-400 \mathrm{mg} / \mathrm{kg}$ of aqueous extract of $B$. diffusa, $1 \mathrm{~h}$ before the intra-peritoneal injection of $200 \mathrm{mg} / \mathrm{kg} /$ day of acetaminophen, for 14 days. For group II rats, in place of single daily intraperitoneal dose of $200 \mathrm{mg} / \mathrm{kg}$ of acetaminophen, 10 $\mathrm{ml} / \mathrm{kg} /$ day of normal saline was administered, for 14 days. Administration of acetaminophen to rats induced marked detritions of renal function, characterized by a significant increase in blood urea nitrogen (BUN), serum creatinine $(\mathrm{p}<0.01)$ and injured the renal cells evident from increased level of kidney malondialdehyde (MDA), protein thiol $(\mathrm{p}<0.01)$ along with depletion of super oxide dismutase (SOD), catalase (CAT), glutathione peroxidase $(\mathrm{GPx})$ activities and reduced glutathione (GSH) levels $(\mathrm{p}<0.01$ ), however pre-treatment with $B$. diffusa extract protected against these changes. Histopathological changes showed that acetaminophen caused significant structural damages to kidneys like tubular necrosis, degeneration of epithelial cells, glomerular damage and congestion which was reversed with $B$. diffusa. The results suggest that $B$. diffusa has the potential in preventing the acetaminophen-induced nephrotoxicity. ${ }^{14}$ In another study, the methanolic extract of roots of $B$. diffusa for its nephroprotective and nephrocurative effects in cisplatin $(10 \mathrm{mg} / \mathrm{kg} \mathrm{b}$. w. i. p.) induced nephrotoxicity in albino rats. Nephrocurative and nephroprotective potential of Boerrhavia diffusa extract (BDE) was evaluated by monitoring the parameters serum urea, createnin, blood urea nitrogen and antioxidant parameters like lipid per-oxidation, super oxide dismutase (SOD), catalase and NO scavenging activities. Treatment with single dose of cisplatin led to significant $(\mathrm{P}<0.001)$ increase in the values of blood urea, serum createnine and blood urea nitrogen. These elevated values were found to be significantly $(\mathrm{P}<0.001)$ reduced and the levels of antioxidant parameters viz. superoxide dismutase, Catalase, Lipid per-oxidation and nitric oxide levels, were found to be equivalent to healthy animals due to treatment with $300 \mathrm{mg} / \mathrm{kg}$ b. w. p. o of extract of $B$. diffusa roots. ${ }^{15}$

\section{Brihat Gokshura (Pedalium murex)}

The ethanolic extract of dried fruits of Pedalium murex Linn was evaluated for its nephroprotective activity. Nephrotoxicity was induced in Wistar rats by intraperitoneal administration of cisplatin $5 \mathrm{mg} / \mathrm{kg}$. Effect of concurrent administration of Pedalium murex ethanolic extract at a dose of $250 \mathrm{mg} / \mathrm{kg}$ given by oral route was determined using serum creatinine and blood urea and change in body weight as indicators of kidney damage. Cystone was used as standard drug. The extract significantly decreased the cisplatin induced 
nephrotoxicity. The results showed that the ethanolic extract of dried fruits of Pedalium murex has an excellent nephroprotective activity as compared to cystone. ${ }^{16}$

\section{Sahadevi (Vernonia cinerea)}

The alcoholic extracts of aerial parts of Vernonia cinerea have been examined for its effect on cisplatin-induced nephrotoxicity at a dose of $6 \mathrm{mg} / \mathrm{kg}$, i. p. in albino rats. The alcoholic extract showed pronounced curative activity and the ethyl acetate extract has exhibited good prophylactic activity and petroleum ether extract showed moderate protection for both curative and prophylactic models against cisplatin-induced toxicity. ${ }^{17}$

\section{Pashanbheda (Aerva lanta)}

The ethanolic extract of the entire plant of Aerva lanata was studied for its nephroprotective activity in cisplatin and gentamicin induced acute renal injury in albino rats of either sex. In the curative regimen, the extract at dose levels of 75,150 and $300 \mathrm{mg} / \mathrm{kg}$ showed dose-dependent reduction in the elevated blood urea and serum creatinine and normalized the histopathological changes in the cisplatin model. In the gentamicin model the rats in the preventive regimen also showed good response to the ethanol extract at $300 \mathrm{mg} / \mathrm{kg}$. The results suggest that the ethanolic extract of Aerva lanata possesses marked nephroprotective activity with minimal toxicity and could offer a promising role in the treatment of acute renal failure caused by nephro-toxins like cisplatin and gentamicin. ${ }^{18}$

\section{Shunti (Zingiber officinale)}

The effect of ethyl acetate extract of fresh rhizomes of Zingiber officinale and dried fresh juice of fresh rhizomes of Zingiber officinale was evaluated for its protective effects on gentamicin induced nephrotoxicity in Wistar rats. Nephrotoxicity was induced by i.p. administration of gentamicin $100 \mathrm{mg} / \mathrm{kg} /$ day for eight days. Effect of concurrent administration of ethyl acetate extract and fresh juice extract of Zingiber officinale at a dose of 200 $\mathrm{mg} / \mathrm{kg} /$ day given by oral route. Gentamicin-induced glomerular congestion, peritubular and blood vessel congestion, epithelial desquamation, accumulation of inflammatory cells and necrosis of the kidney cells were found to be reduced in the groups receiving the ethyl acetate and dried fresh juice extract of Zingiber oficinale along with gentamicin. The extracts also normalized the gentamicin induced increase in serum creatinine, serum uric acid, blood urea nitrogen and serum urea levels. Both the extracts and juice possess significant nephroprotective activity. ${ }^{19,20}$

\section{CONCLUSION}

The studies of herbal drugs listed in this review paper are although of preliminary nature and most of them are experimental studies on animal model. However it shows great potential of Ayurvedic immunomodulator and nephroprotective herbal drugs that can be used to treat steroid dependent / steroid resistant NS cases or at least, preserve its renal function and slow its progression to end stage renal disease. It may be used as add on therapy with modern therapeutic drugs for more efficacious and safety profile in such patients. Therefore the comprehensive clinical trials of Ayurvedic polyherbal formulations can gain importance as one of the better alternative management after proper scientific validation. Further researches (particularly clinical studies) are indicated to support or refute the hypotheses presented in this article.

\section{REFERENCES}

1. Eddy AA, Symons JM. Nephrotic syndrome in childhood. Lance 2003; 362: 629-39. http://dx.doi.org/10.1016/S0140-6736(03) 14184-0

2. Arvind Bagga, Mukta Mantan. Nephrotic syndrome in children. Indian Journal of Medical Research 2005; 122: 13-28.

3. Consensus Statement on Management of Steroid Sensitive Nephrotic Syndrome. Report By Indian Pediatric nephrology group. Indian Pediatrics 2001; 38: 975- 986.

4. Bagga A, Srivastava RN. Nephrotic syndrome. In: Srivastava RN, Bagga A, editors. Pediatric Nephrology. $4^{\text {th }}$ ed. New Delhi: Jaypee; 2005. p. 159-200.

5. Srivastava RN, Mayekar G, Anand R, Choudhry VP, Ghai OP, Tandon HD. Nephrotic syndrome in Indian children. Archives of Disease in Childhood 1975; 50: 626-30. http://dx.doi.org/ 10.1136/adc.50.8.626

6. Hamsa TP, Kuttan G. Tinospora cordifolia ameliorates urotoxic effect of cyclophosphamide by modulating GSH and cytokine levels. Experimental and toxicologic Pathology 2012; 64(4): 307-14. http://dx.doi.org/10.1016/j.etp.2010.09.003

7. Thangavel Jeyanthi, Perumal Subramanian. Nephroprotective Effect of Withania somnifera: A Dose-Dependent Study. Renal Failure 2009; 9: 814-821. http://dx.doi.org/10.3109/08860220903150320

8. Leemol Davis, Girija Kuttan. Immunomodulatory activity of Withania somnifera. Journal of Ethno pharmacology 2000; 71(1, Suppl 2): 193-200. http://dx.doi.org/10.1016/S0378-8741(99)002 06-8

9. Aml F Elgazar, Alaa O, Abo Raya. Nephroprotective and Diuretic Effects of Three Medicinal Herbs against Gentamicin-Induced Nephrotoxicity in Male Rats. Pakistan Journal of Nutrition 2013; 12(8): 715-722. http://dx.doi.org/10.3923/pjn.2013.715.722

10. NN Pathak, SR Rajurkar, S Tarekh, VV Badgire. Nephroprotective Effects of Carvedilol and Curcuma longa against Cisplatin-Induced Nephrotoxicity in Rats. Asian Journal of Medical Science 2014; 5(2): 91-98.

11. Shelkea TT, Bhaskarb VH, Adkara PP, Jhaa U, Oswala RJ. Nephroprotective activity of ethanolic extract of stem barks of Crataeva nurvala Buch Ham. International Journal of Pharmaceutical Sciences and Research 2011; 2(10): 2712-17.

12. Joy J, Nair CK. Amelioration of cisplatin induced nephrotoxicity in Swiss albino mice by Rubia cordifolia extract. Journal of Cancer Research and Therapeutics 2008; 4(3): 111-5. http://dx.doi .org/10.4103/0973-1482.43139

13. Singh RG, Singh P, Singh PK, Usha Agrawal A, Upadhyay BN, Soni A. Immunomodulating and Antiproteinuric Effect of Hippophae rhamnoides (Badriphal) in Idiopathic Nephrotic Syndrome. Journal of the Association of Physicians of India 2013; 61(6): 397-399.

14. Pareta S, P Kartik, Harwansh R, M Kumar, KP Meena. Protective Effects of Boerhaavia diffusa against Acetaminophen-Induced nephrotoxicity in Rats. Pharmacology online 2011; 2: 698-706.

15. Babu Bowlekar, P Harihar, Gadgoli C. Amelioration of Cisplatin Induced Nephrotoxicity by Standardized Methanolic Extract of Roots of Boerhaavia diffusa. The Natural products Journal 2014; 4(3): 217-223. http://dx.doi.org/10.2174/22103155046661410 17000813

16. Shelke TT, Kothai R, Adkar PP, Bhaskar VH, Juvale KC, Kamble BB and Oswal R. J. Nephroprotective activity of ethanolic extract of dried fruits of Pedalium murex Linn. Journal of Cell and Tissue Research 2009; 9(1): 1687-1690.

17. Sreedevi A, Bharathi K, Prasad KVSRG. Effect of Vernonia cinere aerial parts against Cisplatin-induced nephrotoxicity in rats. Pharmacology online 2011; 2: 548-555. 
18. Shirwaikar A, Issac D, Malini S. Effect of Aerva lanata on cisplatin and gentamicin model of acute renal failure. Journal of Ethno pharmacology 2004; 90 (1): 81-6. http://dx.doi.org/10.1016 /j.jep.2003.09.033

19. BVS Lakshmi, M Sudhakar. Protective Effect of Zingiber oflicinale on Gentamicin-Induced Nephrotoxicity in Rats. International Journal of Pharmacology 2010; 6(1): 58-62. http://dx.doi.org/ 10.3923/ijp.2010.58.62
20. Das Arpita, Mukerjee Tirtha, Sadhu Saugata. Pharmacognostical and phytochemical screening of trikatu herbs, the healing touch of Ayurveda. Int J Res Ayurveda Pharm 2011; 2(4): 1390-1394.

Cite this article as:

Choudhary Kuldeep, Dwivedi Avneesh, Sharma Abhisekh. Herbal approach in management of nephrotic syndrome. Int. J. Res. Ayurveda Pharm. 2015;6(2):169-173 http://dx.doi.org/10.7897/2277-4343.06233

Source of support: Nil, Conflict of interest: None Declared 